\title{
THE INFLUENCE OF SPECIES DIVERSITY AND STRESS INTENSITY ON COMMUNITY RESISTANCE AND RESILIENCE
}

\author{
GARy AlLison \\ Aquatic Ecology Laboratory, Department of Evolution, Ecology and Organismal Biology, \\ The Ohio State University, Columbus, Ohio 43210 USA
}

\begin{abstract}
Recent theory, such as the insurance hypothesis, suggests that higher species diversity may dampen perturbation dynamics within a community. The dynamics of a rocky intertidal macroalgal community were evaluated using an experimentally induced heat stress applied at the end of a 15-mo manipulation of diversity. This pulse event produced a gradient of thermal stress within plots and, consequently, different degrees of perturbation. In general, the resistance of the community to the thermal stress was forecast by the pre-stress cover of dominant species, total algal cover, and standing biomass. Because higher diversity treatments, especially those containing the dominant algal group, fucoids, had higher overall abundance, highest diversity treatments were the most severely affected. The stress was also relatively nonselective, in that species were reduced in roughly equivalent proportions, suggesting an important distinction for predicting when diversity will not influence disturbance dynamics. The resilience of the community was strongly dependent on which species were initially present in the plots and the degree of disturbance. In highly disturbed areas, although the recovery trajectory was similar in early successional stages, differences emerged later; these differences appear to be attributable to the composition of the surrounding regeneration pool. For treatments not receiving the thermal stress, low-diversity plots without fucoids remained in states unlike the reference condition for most of the monitored resilience period. But plots in high-diversity treatments, even areas within plots that had experienced moderate disturbance, returned to states similar to the reference quickly. Thus, resilience (but not resistance) results are consistent with the insurance hypothesis. Overall, diversity's influence on community dynamics is complex and will depend on the characteristics of the stress as well as the characteristics of the species present in the community.
\end{abstract}

Key words: disturbance; diversity manipulation; diversity-stability; macroalgae; Oregon; resilience; resistance; rocky intertidal community; thermal stress.

\section{INTRODUCTION}

While diversity-stability relationships have been a longstanding focus of both theoretical and empirical work (e.g., Elton 1958, May 1973, Pimm 1984, McNaughton 1993), recent progress has been rapid on both fronts. Theory now identifies at least two general classes of mechanisms for potential relationships (Loreau et al. 2001): those involving some form of species "complementarity," such as the insurance hypothesis (e.g., Yachi and Loreau 1999), and those concerning probabilistic or sampling relationships (e.g., Tilman et al. 1997, Doak et al. 1998). Also, the number of stability components considered within this work has broadened with theory tackling implications of diversity's interaction with general environmental variability as well as specific perturbation dynamics (e.g., Loreau and Behera 1999). Further, by using innovative designs with constructed communities, experimenters have avoided problems that confounded interpretation in earlier experiments. Consequently, the field has begun to accumulate tests of the effect of diversity on

Manuscript received 1 November 2002; revised 28 March 2003; accepted 7 April 2003. Corresponding Editor: R. J. Etter. temporal variability (McGrady-Steed et al. 1997, Naeem and Li 1997), on susceptibility to invasive species (McGrady-Steed et al. 1997, Knops et al. 1999, Stachowicz et al. 1999, Levine 2000), and on resistance and resilience (Petchey et al. 1999, Griffiths et al. 2000, Mulder 2001, Pfisterer and Schmid 2002; A. L. Downing and M. A. Leibold, unpublished manuscript). Because of this bloom of new work, conditions may be ripe for significant resolution of this longstanding and often contentious topic (Loreau et al. 2002).

However, general conclusions are still preliminary (Loreau et al. 2001, Tilman et al. 2001). While designs with constructed communities eliminate many potential interpretation issues, it is not clear how applicable they are to natural systems where environmental variability may swamp any predicted diversity effects. Recent designs using randomized diversity gradients permit interpretation about diversity per se, but they make interpretations about the role of individual species or particular compositions difficult (Allison 1999, Loreau et al. 2001). Furthermore, empirical examples are mostly from grassland systems and we need tests from many types of systems.

Benthic marine communities have been productive systems in which to study community dynamics and 
TABLE 1. Algal species list and abundance.

\begin{tabular}{|c|c|c|c|c|c|}
\hline Experimental group & Species & Division & $\begin{array}{l}\text { Max. cover in } \\
625-\mathrm{cm}^{2} \\
\text { subsample }(\%)\end{array}$ & $\begin{array}{c}\text { Mean cover } \\
(\%)\end{array}$ & SD (\%) \\
\hline Fucoids & $\begin{array}{l}\text { Fucus spp. } \\
\text { Pelvetiopsis limitata }\end{array}$ & $\begin{array}{l}\text { Phaeophyta } \\
\text { Phaeophyta }\end{array}$ & $\begin{array}{r}100.0 \\
96.8\end{array}$ & $\begin{array}{l}39.2 \\
24.5\end{array}$ & $\begin{array}{l}25.2 \\
23.5\end{array}$ \\
\hline Foliose reds & $\begin{array}{l}\text { Mazzaella cornucopiae } \\
\text { Mastocarpus papillatus }\end{array}$ & $\begin{array}{l}\text { Rhodophyta } \\
\text { Rhodophyta }\end{array}$ & $\begin{array}{l}95.3 \\
87.5\end{array}$ & $\begin{array}{l}15.7 \\
13.7\end{array}$ & $\begin{array}{l}20.0 \\
16.7\end{array}$ \\
\hline Low-abundance species & $\begin{array}{l}\text { Endocladia muricata } \\
\text { Cladophora columbiana } \\
\text { Odonthalia floccosa } \\
\text { Analipus japonicus } \\
\text { Porphyra spp. } \\
\text { Scytosiphon lomentaria } \\
\text { Neorhodomela larix } \\
\text { polysiphonous red spp. } \\
\text { Leathesia difformis } \\
\text { Mazzaella flaccida } \\
\text { Petalonia fascia } \\
\text { erect coralline spp. } \\
\text { Ulva spp. } \\
\text { Callithamnion pikeanum } \\
\text { Prionitis spp. } \dagger \\
\text { Blidingia minima } \dagger \\
\text { Halosaccion glandiforme } \dagger\end{array}$ & $\begin{array}{l}\text { Rhodophyta } \\
\text { Chlorophyta } \\
\text { Rhodophyta } \\
\text { Phaeophyta } \\
\text { Rhodophyta } \\
\text { Phaeophyta } \\
\text { Rhodophyta } \\
\text { Rhodophyta } \\
\text { Phaeophyta } \\
\text { Rhodophyta } \\
\text { Phaeophyta } \\
\text { Rhodophyta } \\
\text { Chlorophyta } \\
\text { Rhodophyta } \\
\text { Rhodophyta } \\
\text { Chlorophyta } \\
\text { Rhodophyta }\end{array}$ & $\begin{array}{r}78.1 \\
60.9 \\
31.3 \\
1.6 \\
7.8 \\
9.4 \\
1.3 \\
4.7 \\
6.3 \\
3.4 \\
1.6 \\
1.6 \\
1.6 \\
1.6 \\
0.0 \\
0.0 \\
0.0\end{array}$ & $\begin{array}{l}9.5 \\
6.2 \\
0.25 \\
0.24 \\
0.14 \\
0.13 \\
0.12 \\
0.10 \\
0.094 \\
0.049 \\
0.023 \\
0.013 \\
0.013 \\
0.007 \\
0.0 \\
0.0 \\
0.0\end{array}$ & $\begin{array}{l}12.0 \\
10.3 \\
1.83 \\
0.56 \\
0.57 \\
0.63 \\
0.79 \\
0.49 \\
0.52 \\
0.3 \\
0.187 \\
0.14 \\
0.14 \\
0.10 \\
0.0 \\
0.0 \\
0.0\end{array}$ \\
\hline
\end{tabular}

Notes: Mean, standard deviation, and maximum cover were calculated from all $\left(625-\mathrm{cm}^{2}\right)$ subsamples and from four census dates in 1993-1994 measured in 15 reference plots. Cover estimates included layering, so total cover within a plot is often $>100 \%$. Maximum cover was calculated from subsamples from all plots in July 1993. Species are ordered by mean abundance.

$\dagger$ Species shown with mean of zero occurred in other treatments during this period, although at low abundance $(<3 \%)$.

responses to physical stresses under natural settings (Sousa 1979, Paine and Levin 1981, Menge and Sutherland 1987, Menge et al. 2002, Guichard et al. 2003). These communities often have a relatively rapid recovery rate from perturbations, have organisms that are relatively easy to manipulate, and are of a convenient scale for experiments (Connell 1974). Furthermore, natural disturbances are common in many of these communities, and a great deal is already understood about their disturbance and succession dynamics (see Sousa 2001 for a comprehensive review). The community dynamics evaluated in this paper are resistance, the magnitude of change caused by an environmental stress, and resilience, how quickly the community recovers from the stress (Holling 1973, Orians 1975, Pimm 1991, Tilman and Downing 1994). These factors, to some extent, determine spatial and temporal dynamics of a community through the degree of fluctuations from a given perturbation and the proportion of a community recovering at any given time (Guichard et al. 2003). Such dynamics will, in turn, influence many properties of communities such as their long-term persistence (Pimm 1991) and their structure (Levin and Paine 1974).

Here, I present the results of an experiment in the high zone of a rocky intertidal community in which a thermal stress was applied to experimental plots that differed in diversity. This diversity gradient was created by a prior manipulation of macroalgal species composition. While the design does not permit direct attribution of effects to diversity per se as in a random diversity gradient approach, the design allows me to evaluate specific compositional effects of a given treatment within a diversity context (Allison 1999). I determined the magnitude of the effects of the thermal stress on the different compositional treatments and followed the recovery of the community from the stress. The design of this experiment allowed me to evaluate community dynamics in response to two types of deviation from a reference condition: environmental stress and species deletion. The questions addressed with this experiment are: How does composition influence the magnitude of the effect of this pulse perturbation? Were species differentially affected by the stress? How does composition interact with the stress level to influence recovery from the perturbation?

\section{System Description}

I performed this study in the high intertidal zone of the rocky benches of Fogarty Creek Point (44⒌ $51^{\prime} \mathrm{N}$, $124^{\circ} 03^{\prime} \mathrm{W}$ ) on the central coast of Oregon, USA. Macroalgae and acorn barnacles dominate the high zone. The predominant algal species are the fucoids, Fucus gardneri and Pelvetiopsis limitata, and the foliose red species, Mastocarpus papillatus and Mazzaella (= Iridaea) cornucopiae, which together comprise $\sim 94 \%$ cover on average (including overlapping layers). $\mathrm{Nu}-$ merous other macroalgal species also exist in this zone, though usually at low abundance (Table 1). Common nonalgal species that occurred in experimental plots included acorn barnacles Balanus glandula and Chthamalus dalli, limpets Lottia digitalis, L. pelta, and 
TABLE 2. Experimental treatment structure and the diversity within treatments.

\begin{tabular}{|c|c|c|c|c|c|c|c|}
\hline \multirow[b]{2}{*}{ Treatment code } & \multirow[b]{2}{*}{$\begin{array}{l}\text { Treatment } \\
\text { level }\end{array}$} & \multicolumn{3}{|c|}{ Algal groups manipulated } & \multirow[b]{2}{*}{$\begin{array}{l}\text { Mean species } \\
\text { richness (SE) }\end{array}$} & \multirow[b]{2}{*}{$\begin{array}{l}\text { Mean algal wet } \\
\text { biomass (SE) }\end{array}$} & \multirow{2}{*}{$\begin{array}{l}\text { Biomass } \\
\text { multiple } \\
\text { range test }\end{array}$} \\
\hline & & Fucoids & $\begin{array}{l}\text { Foliose } \\
\text { reds }\end{array}$ & $\begin{array}{l}\text { Minor } \\
\text { species }\end{array}$ & & & \\
\hline High: $+F+R+M$ & high & + & + & + & $27.4(1.81)$ & $631.5(22.9)$ & $\mathrm{A}$ \\
\hline Mid1: $-F+R+M$ & moderate & - & + & + & $24.3(2.00)$ & $298.1(15.5)$ & $\mathrm{B}, \mathrm{C}$ \\
\hline Mid2: $+F+R-M$ & moderate & + & + & - & $18.9(0.43)$ & $600.3(27.9)$ & A \\
\hline Low 1: $+\mathrm{F}-\mathrm{R}-\mathrm{M}$ & low & + & - & - & $15.0(1.02)$ & $409.7(43.1)$ & B \\
\hline Low $2:-\mathrm{F}+\mathrm{R}-\mathrm{M}$ & low & - & + & - & $13.3(0.75)$ & $250.0(17.3)$ & $\mathrm{C}$ \\
\hline
\end{tabular}

Notes: All macroalgal species were lumped into one of three groups: fucoids = Fucus spp. and Pelvetiopsis limitata; foliose reds = Mastocarpus papillatus, Mazzaella $(=$ Iridaea) cornucopiae ; or minor species = all other macroalgal species (see Table 1 for a complete list). Groups included in the treatment are indicated by "+," groups excluded from the treatment are indicated by "-." Mean species richness (and standard error, SE) per plot throughout the diversity press phase includes all macro-flora and fauna except very small or highly mobile species. Mean algal biomass $\left(\mathrm{g} / 0.25 \mathrm{~m}^{2}\right.$ and $\left.\mathrm{SE}\right)$ is reported for the end of the diversity press (August 1994) as well as significant differences from a Duncan multiple range test. Throughout this paper, either the full codes (e.g., "Low1: $+\mathrm{F}-\mathrm{R}-\mathrm{M}$ ") or the reduced codes (e.g., "Low1") are used to refer to the diversity treatments. In the full codes, "F" refers to fucoid, "R" to foliose reds, and "M" to minor species group.

L. strigatella, herbivorous snails Littorina spp., and the predatory snail Nucella ostrina. The experiment was performed across an extensive portion of the site at moderate wave exposure.

\section{METHODS \\ Macroalgal groups}

To create a diversity gradient, I divided macroalgae into three groups. Species in the first two groups were chosen for their morphological similarity, while the third group contained all other species and was thus highly diverse.

Fucoids.-The first group consisted of fucoid species (Order Fucales): mostly Fucus gardneri and Pelvetiopsis limitata with some Fucus spiralis occurring in more wave-protected areas. Fucoids are relatively large, have a leathery thallus, and often form a canopy that covers understory species. $P$. limitata typically occurs higher on the shore than $F$. gardneri, although there is substantial overlap at this site. The mean unmanipulated cover for this group of species was $64 \%$.

Foliose reds.-The second group consisted of the common red foliose species (Order Gigartinales): Mastocarpus papillatus and Mazzaella (= Iridaea) cornucopiae. Both species are abundant in the high intertidal zone of the open coast in this region. Both develop from fleshy crusts into a compact aggregation of blades. The turf/crust morphology of these species allows them to persist through heavy grazing and physical stresses (Lubchenco and Cubit 1980, Hay 1981, Olson 1985). The mean unmanipulated cover for this group of species was $30 \%$.

Minor species.-The third group consisted of all other macroalgal species (Table 1). In this group, two species were present in most plots: Endocladia muricata (Order Gigartinales) is a perennial red alga with dense bushy thalli that can form thick mats (Glynn 1965) but were more typically distributed patchily in the experimental plots. Cladophora columbiana is a green filamentous alga that forms dense mats. Cover of $C$. co- lumbiana is relatively seasonal, peaking in late spring and summer. Its dense mat morphology acts like a sponge and can hold a large amount of water. Other species in this group, although occasionally present in a substantial portion of one or a few subplots, had mean covers of $<1 \%$. Unmanipulated cover for this group averaged $17 \%$.

\section{Diversity treatments}

I created an experimental gradient of diversity by removing macroalgal species from initially high-diversity plots. Fifty $1-\mathrm{m}^{2}$ plots were used to create five treatments in a randomized block design with two replicates per block. I created different diversity treatments by removing different numbers of the three algal groups. A high-diversity treatment had all three groups, a mid-diversity treatment had two groups, and a lowdiversity treatment had only one of the three algal groups. Different combinations of these groups formed two different mid-diversity treatments and two different low-diversity treatments (Table 2). A full factorial design was not possible because of limited experimental space at this site. Each plot had a $13-\mathrm{cm}$ buffer around its edge. All manipulations were also performed on the buffer but data were taken only from the central $1 \mathrm{~m}^{2}$. An additional fifteen $1-\mathrm{m}^{2}$ plots were marked and monitored to serve as a reference for both the diversity and stress manipulations.

In spring 1993, to initiate the diversity treatments, I performed a calibrated removal in all treatment plots. First, I manually removed the excluded groups including as much of their basal crusts as possible. Then, to control for bare space created by the initial removals, I created the same amount of bare space in all plots. I did this by first calculating the change in bare space for all plots after the initial removals. Then, I added more bare space in $5 \times 5 \mathrm{~cm}$ squares randomly assigned throughout the plot until all plots had the same amount (34\%). I standardized to equal bare space instead of some other factor such as total canopy cover or total 
biomass because bare space in rocky intertidal communities is a major factor limiting intra- and interspecific competition.

Throughout the subsequent $15 \mathrm{mo}$, treatments were maintained by carefully removing all recruits of the excluded species from within each plot. All excluded recruits were removed from plots at least every two weeks. Algal crusts were not manipulated during this maintenance weeding. I allowed recruitment of nonexcluded species throughout the plots, including into the bare space created at the initiation of the diversity treatments.

Throughout the experiment, the percent cover of all species in two $0.25-\mathrm{m}^{2}$ subplots per plot was estimated in a spatially explicit manner using a grid of 256 uniform points. Sampling precision was sufficient to follow patches larger than $40 \mathrm{~cm}^{2}$ over time by clustering sets of individual grid points. The datum collected for each grid point was the presence of all species that intersected the point.

\section{Stress treatment}

At the end of the diversity press phase (August 1994), one replicate from each block for each diversity treatment was randomly selected for a control group and the other replicate was used for the stress treatment group. The stress applied to the latter group was a pulse thermal stress created by low-power (5000 BTU) propane heaters. One heater was suspended over each of the four $0.25-\mathrm{m}^{2}$ subplots of a $1-\mathrm{m}^{2}$ plot and heat was applied for $90 \mathrm{~min}$. The sequence of heating across the experiment was randomly assigned within blocks. To control for variance in emersion time, plots were hydrated with copious seawater $30 \mathrm{~min}$ before the heat stress.

During the stress treatment, a chamber was secured over the heated subplots to control ambient temperature and to block wind and precipitation. The chamber was $0.7 \mathrm{~m}$ wide $\times 1.2 \mathrm{~m}$ long $\times 1 \mathrm{~m}$ high, allowing it to be secured over two subplots at a time, and was constructed of two layers of clear plastic sheeting over a frame of PVC pipe. The propane heaters were suspended within this chamber, $40 \mathrm{~cm}$ above and facing the substratum. The ambient temperature within the chamber was measured with a thermometer suspended $50 \mathrm{~cm}$ above the substratum and was maintained below $35^{\circ} \mathrm{C}$ using adjustable vents constructed in the plastic sheeting. This ambient temperature rarely reached $30^{\circ} \mathrm{C}$ sooner than 45 min after the start of the stress.

The heaters produced a strong temperature stress. By the end of the 90-min treatment, the surface of organisms directly under the heaters averaged $42^{\circ} \mathrm{C}(n=25$; maximum $49^{\circ} \mathrm{C}$ ), although organism temperatures under the algal canopy in the same location were typically $10-15^{\circ} \mathrm{C}$ cooler than the surface of the canopy. Locations away from the center of the subplots were cooler: the canopy surface halfway to the edge of the sub- plot averaged $36^{\circ} \mathrm{C}(n=25)$ and the surface at the edge of the subplot averaged $32^{\circ} \mathrm{C}(n=25)$.

\section{Biomass calculation}

To estimate standing algal biomass in experimental plots nondestructively, I generated a regression equation that related algal cover to algal biomass. This equation was developed by surveying, then destructively sampling 28 quadrats $\left(625 \mathrm{~cm}^{2}\right)$ in unmanipulated areas. These samples were chosen to span the range of algal cover and species mixes found in the experimental plots. After each quadrat was surveyed, all algae were collected from the quadrat, returned to the lab, cleaned of epifauna, dried of excess moisture, and wet weighed. I used stepwise linear regression to determine the best fit between biomass and cover estimates. The resulting equation for total standing wet algal biomass $\left(B_{\text {wet }}\right)$ in grams $/ 0.25 \mathrm{~m}^{2}$ was

$$
B_{\text {wet }}=431.0 C+545.7 F
$$

(model $P<0.0001 ; R^{2}=0.869 ; R^{2}$ for the model with an intercept included was 0.634 ), where $C$ is the proportional cover of all algae and $F$ is the proportional cover of fucoid plants.

\section{Analysis}

Translating the theoretical concepts of resistance and resilience (Holling 1973, Pimm 1991) to an experimental context can be difficult. Here, resistance is simply the magnitude of the proximate effects of a perturbation (e.g., Farrell 1988, Frank and McNaughton 1991, McNaughton 1993, Tilman and Downing 1994), specifically, the magnitude of change in species and community measures immediately following the thermal stress. Further, comparison of resilience among treatments was made using the change in community composition and state following the resistance phase.

In this experiment, because the stress applied was of short duration, it was possible to decouple resistance from resilience dynamics. To compare the magnitude of stress effects, it is important to use comparisons where stress intensity is similar (Connell and Sousa 1983), whereas to measure recovery from a perturbation, it is important to compare areas that were disturbed by similar degrees. Because these are not necessarily the same, I partitioned the data differently for resistance and resilience analyses. For the resistance analysis, I partitioned the survey data within each subplot into three heat-intensity levels (harsh, intermediate, and mild in areas radiating from the center of a subplot, respectively). As a control in the resistance analysis, the variables from the nonheated control plots (thermal control) were averaged from each of these three regions.

For the resilience analysis, I partitioned data into two levels based on degree of actual perturbation within individual subplots. For the severe level, I included just those areas within a subplot that experienced a 
TABLE 3. Community "states" and criteria for classification.

\begin{tabular}{ll}
\hline \hline \multicolumn{1}{c}{ State (code used in figures) } & \multicolumn{1}{c}{ Cover criteria } \\
\hline Rock dominated (R) & total algae $<0.3$ and barnacle $<0.3$ \\
Barnacle dominated (B) & total algae $<0.3$ and barnacle $>0.3$ \\
Balanus/Endocladia dominated (B/E) & Balanus $>0.4$ and Endocladia $>0.3$ and total non-Endocladia algae $<0.3$ \\
Cladophora dominated (C) & Cladophora $>0.4$ \\
Foliose red dominated (FR) & (Mastocarpus $>0.4$ or Mazzaella $>0.4$ or (Mastocarpus + Mazzaella) $>$ \\
Fucoid dominated (F) & 0.6) and (Mastocarpus + Mazzaella) $>$ fucoid \\
\hline
\end{tabular}

Notes: State classification is progressive; that is, states on the bottom of the list are assigned only if the criteria for the states above are not met. All criteria are measures of cover: "total algae" is the additive cover of all algal species; "barnacle" is the cover of Balanus glandula, Chthamalus dalli, Semibalanus cariosus, and Pollicipes polymerus. The few experimental units that were not classified by this scheme were evaluated individually; most were of sparse algal cover and were assigned to the "rock" state.

dramatic change in cover. These areas satisfied the following criteria: (1) a survey grid point was included in the area if it had been occupied by an organism for the two surveys before the thermal stress, but was unoccupied after the stress, (2) it was contiguous with at least two other such points, (3) the set of these grid points was at least 40 in number $\left(\approx 400 \mathrm{~cm}^{2}\right)$, and (4) $90 \%$ of the grid points within the perimeter of the selected area were bare after the stress. The size of these selected areas was not significantly different among treatments $\left(F_{8,28}=1.23, P=0.3\right.$, mean $=722 \mathrm{~cm}^{2}, 1$ $\mathrm{SE}=34.5, n=37)$. The second data partition in the stressed plots (moderate; mean size $=1720 \mathrm{~cm}^{2}, 1 \mathrm{SE}$ $=29.6, n=50$ ) excluded all grid points that occurred in the severe data set or in the harsh data set (as defined in the resistance analysis).

To test for resistance differences among diversity treatments, I performed MANOVA on the absolute change in community and species measures. Although a full MANOVA model that included all dependent variables would have been desirable to account for covariance among dependent variables, such an analysis was not possible because several species variables were explicitly manipulated in some treatments. As a compromise, therefore, I performed separate MANOVA analyses on three groups of related variables (community variables, fucoids, and foliose red algae). I checked the normality of data visually and by the Shapiro-Wilk statistic. Homogeneity of variances was verified with residual plots and transformations were not needed. Because heat levels within each subplot were spatially correlated, I could not treat them independently. Therefore, when comparisons were made to nonheated controls, I performed separate analyses on each heat level compared to the controls and adjusted the $P$ values for multiple comparisons using the DunnSidák method (Sokal and Rohlf 1981).

I used principal components analysis (PCA) to compare the broad community differences between diversity treatments and perturbation levels. Each ordination includes the reference plots as well as all treatments within a perturbation level for a given date. The variables used in this analysis were measures of standing wet algal biomass, species richness, and the cover of canopy, fucoids, foliose reds, minor algal species, and barnacles. To adjust for variables of different scales, all values were rescaled to each variable's maximum. Required transformations are indicated in the figure captions.

The effects of the perturbation level and the diversity treatments on resilience were further explored by identifying the major community states that occurred across the experiment and categorizing all experimental units into one of these states at several time points throughout the resilience period. First, I performed a cluster analysis (Euclidean distance and Ward's group linkage methods) to partition all survey points into a manageable number of community states. The data used in this cluster analysis were proportional cover of all species whose abundance was $>10 \%$ in at least $10 \%$ of the plots (Fucus, Pelvetiopsis, Mastocarpus, Mazzaella, Endocladia, Cladophora, Balanus glandula, and Chthamalus dalli). These data were rescaled to equalize the maximum abundance of all species. The generated dendrogram was then used to identify the major groupings in the entire set. I combined some of the 11 major groupings into a single state. For example, I collapsed the three groupings, Mastocarpus dominated, Mazzaella dominated, and Mastocarpus and Mazzaella dominated, into the single state "foliose red dominated." Using these groupings, I developed a set of numeric criteria to classify all dates of all treatments into one of six states (Table 3 ). The characteristics of the states are:

1) Bare rock dominated. These areas were either completely bare or had sparse cover of sessile organisms. Patches of bare rock are often heavily grazed by limpets (Farrell 1989, Kim and DeWreede 1996). Barnacles or ephemeral algae usually quickly colonize such patches.

2) Barnacle dominated. This is a typical early successional stage after free space is created. In these areas, high cover of barnacles can reduce grazing by limpets and can also serve as recruitment substrate for several species (e.g., Endocladia, fucoids) (Dayton 1971, Farrell 1991). 
3) Balanus/Endocladia dominated. While common in rocky intertidal areas of the northeast Pacific (Glynn 1965), often as a late successional state, this state was not prevalent in the experimental areas. More often, plots in this state were either colonized by fucoids or, in areas of dense Endocladia mats, barnacles were smothered by Endocladia and eventually sloughed off the rock leaving a rock-dominated area (G. Allison, personal observation).

4) Fucoid dominated. This was the most prevalent state within this experiment and is very common in many high intertidal communities (Dayton 1971, Farrell 1991, Chapman 1995). In more wave-protected areas, fucoids can develop a heavy canopy which may subject other organisms to reduced light and whiplash effects (Dayton 1971, Kim and DeWreede 1996) but also may reduce desiccation stress for organisms under the canopy.

5) Foliose red dominated. When Mastocarpus and Mazzaella are abundant in plots, the plants often have a dense cluster of blades and can dominate primary space with thick crusts and dense holdfasts (Hay 1981; G. Allison, personal observation). While fucoids can be present in such areas, fucoid recruits occur mostly at edges of Mazzaella patches and outside of dense Mastocarpus patches.

6) Cladophora dominated. These states are often seasonal as Cladophora is most abundant in spring and summer. Other algal species co-occur in Cladophoradominated plots though rarely within the Cladophora mat itself.

\section{RESUlts}

\section{Status at end of diversity press}

Prior to the diversity press, most plots in this experiment were roughly within the range of variation that occurred among the 15 reference plots (Fig. 1A). However, by the end of the diversity press, several treatments (mid1, low1, and low2; Fig. 1B) clustered far from the reference and the variation among these treatments was far greater than that among reference plots. However, the high-diversity treatment as well as several plots of the mid-diversity treatment, mid2, clustered within the reference set. Biomass among the treatments differed significantly (Table 2) with higher diversity treatments, especially those with fucoids, having higher standing biomass.

\section{Immediate effects of the thermal stress}

The application of the thermal stress to each subplot produced intense heat in the center of the subplot, decreasing toward the edges. This stress usually produced considerable mortality and/or tissue damage to sessile and mobile species in the center, but much less damage at the edges. Although this thermal stress was novel in its intensity, the net result on the community was similar to natural disturbances. Natural heat and desicca-

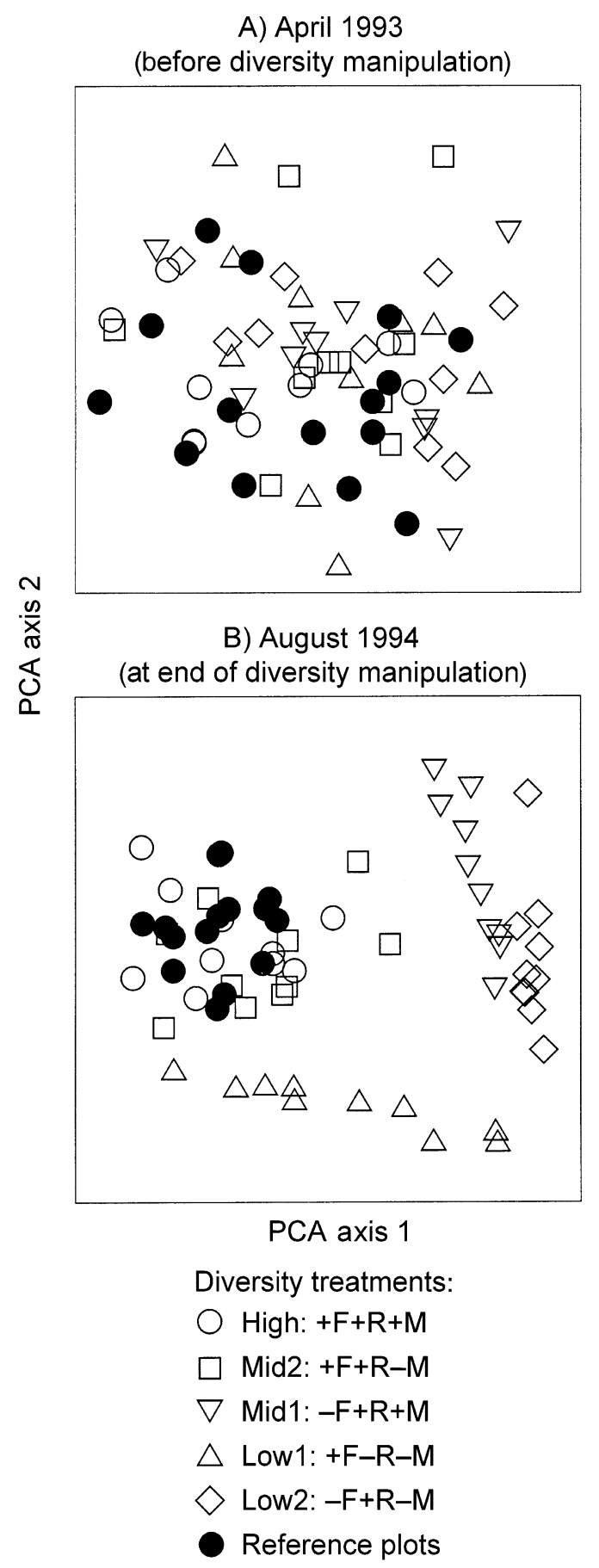

FIG. 1. Principal components analysis of plots before the diversity manipulation and before the stress was applied. PCA was performed on measures of $\ln$ (biomass), total algal cover, and plot species richness, and the arcsine square-root transform of barnacle cover, fucoid cover, foliose red cover, and minor species cover. Values for the reference plots were the means of all surveys. Note that the axes for each ordination are not necessarily the same; because the reference values are the same in all ordinations, those reference values can be used to judge the variance among all plots. Loadings (percent variance) for axis 1 , axis 2 , and the number of significant axes, respectively, are: (A) 41.5, 25.6, 3; (B) 45.6, 33.7, 2. 
TABLE 4. MANOVA analysis of resistance to thermal stress.

\begin{tabular}{|c|c|c|c|c|c|c|c|c|c|c|}
\hline \multirow[b]{3}{*}{ Source } & \multirow[b]{3}{*}{ df } & \multicolumn{9}{|c|}{ Heat-intensity level } \\
\hline & & \multicolumn{3}{|c|}{ Mild } & \multicolumn{3}{|c|}{ Intermediate } & \multicolumn{3}{|c|}{ Harsh } \\
\hline & & $\mathrm{W} \lambda$ & $F$ & $P$ & $\mathrm{~W} \lambda$ & $F$ & $P$ & $\mathrm{~W} \lambda$ & $F$ & $P$ \\
\hline \multicolumn{11}{|l|}{ Community data } \\
\hline Stress & 3,42 & 0.556 & 11.1 & 0.0001 & 0.385 & 22.4 & 0.0001 & 0.282 & 35.7 & 0.0001 \\
\hline Treatment & 15,116 & 0.182 & 6.63 & 0.0001 & 0.175 & 6.81 & 0.0001 & 0.160 & 7.31 & 0.0001 \\
\hline Treatment $\times$ stress & 15,116 & 0.777 & 0.742 & 0.7373 & 0.618 & 1.48 & 0.1257 & 0.467 & 2.46 & $\mathbf{0 . 0 0 3 7}$ \\
\hline Block & 12,111 & 0.545 & 2.39 & 0.0087 & 0.558 & 2.229 & 0.0120 & 0.667 & 0.154 & 0.1213 \\
\hline \multicolumn{11}{|l|}{ Foliose red data } \\
\hline Stress & 2,35 & 0.576 & 12.9 & 0.0001 & 0.489 & 18.3 & 0.0001 & 0.326 & 36.1 & 0.0001 \\
\hline Treatment & 8,70 & 0.483 & 3.83 & 0.0009 & 0.683 & 1.83 & 0.0856 & 0.633 & 2.25 & 0.0336 \\
\hline Treatment $\times$ stress & 8,70 & 0.779 & 1.17 & 0.3291 & 0.839 & 0.800 & 0.6044 & 0.812 & 0.963 & 0.4717 \\
\hline Block & 8,70 & 0.659 & 2.03 & 0.0556 & 0.700 & 1.71 & 0.1124 & 0.696 & 1.74 & 0.1040 \\
\hline \multicolumn{11}{|l|}{ Fucoid data } \\
\hline Stress & 2,27 & 0.566 & 10.3 & 0.0005 & 0.373 & 22.7 & 0.0001 & 0.359 & 21.5 & 0.0001 \\
\hline Treatment & 6,54 & 0.935 & 0.308 & 0.9300 & 0.874 & 0.679 & 0.7065 & 0.956 & 0.207 & 0.9732 \\
\hline Treatment $\times$ stress & 6,54 & 0.916 & 0.403 & 0.8738 & 0.950 & 0.234 & 0.9637 & 0.963 & 0.170 & 0.9837 \\
\hline Block & 8,54 & 0.414 & 3.73 & 0.0015 & 0.403 & 3.88 & 0.0011 & 0.462 & 3.18 & 0.0050 \\
\hline
\end{tabular}

Notes: For each set of variables, three MANOVAs were performed, each comparing one thermal stress level to the thermal controls. Because of this multiple comparison to controls, significance was adjusted by the Dunn-Sidák criteria $(\alpha=0.05$ at $P<0.0169)$. Boldface type indicates a significant effect. W $\lambda=$ Wilks' lambda statistic.

tion stresses can produce very similar results when they cause plant tissue damage, bleaching, and therefore reduction of cover of both species and total canopy (Hay 1981, Olson 1985, Chapman 1995, Davison and Pearson 1996). For example, in late August 1993, temperatures $10^{\circ} \mathrm{C}$ greater than the mean August maximum (measured at NOAA weather station NWPO3 in Newport, Oregon, USA) coincided with low tides and calm wave conditions. Some areas at Fogarty Creek were apparently affected by this event: bleaching and algal mortality was common (G. Allison, personal observation). Other natural disturbances caused by $\log$ s or rocks rolling in the surf may be more severe (Dayton 1971, Paine and Levin 1981, Sousa 1985). The force applied in such disturbances can remove most organisms in the impact area. Each of these disturbances is common in the rocky intertidal of Oregon and produces effects similar to what was seen here: reduction in cover or complete removal of organisms from the rock.

\section{Resistance}

The thermal stress affected virtually all response variables (Table 4). Absolute change in the stressed plots varied predictably with degree of heat stress: loss in harsh zones was higher than loss in mild zones for all measured variables (Figs. 2-4). Defining resistance as the level of perturbation that the community can resist without change, all stress levels overcame the resistance (Table 4; stress is highly significant in all variables).

Responses to diversity treatments were also strong. In particular, the community variables (Table 4) exhibited both treatment effects for all heat levels and a treatment $\times$ stress interaction in the harsh level, suggesting that some diversity treatments were more af- fected than others by the stress. For total algal cover and canopy cover, the two low-diversity treatments were the least affected (Fig. 2). In the case of the standing algal biomass, treatments most strongly affected were those with fucoids, especially the high and mid2 diversity treatments. Thus, the primary direct effect of the stress was the reduction of cover and, for the community variables, the higher diversity treatments were affected the greatest. Simply, the greatest losses from thermal stress were in those areas with the most to lose.

A few other direct effects of thermal stress were notable. There was a treatment effect in the mild stress on the foliose red algal species (Mastocarpus and Mazzaella; Table 4). This effect appears attributable to the presence of the fucoid group: change in Mastocarpus in treatments where fucoids were present (Fig. 3A, "+") was much less than in treatments in which fucoids were absent. This is again attributable to more loss in treatments with higher cover: exclusion of fucoids during the diversity press phase released Mastocarpus from competition and allowed an increase in abundance (Allison 1997). The thermal stress strongly affected the "excess" cover relative to natural cover. Also, significant block differences in the community variables and fucoids suggest the effects varied spatially. There were no treatment effects on the fucoid species (Table 4; Fig. 4).

There was little difference in the relative effect of the thermal stress on the four dominant algal species (Table 5, Fig. 5). Although there was some suggestion of a species difference between the mild heat level and the controls in how Mastocarpus vs. Pelvetiopsis responded to the stress, this trend was not significant. For the most part, the thermal stress was nonselective: 
Diversity treatments
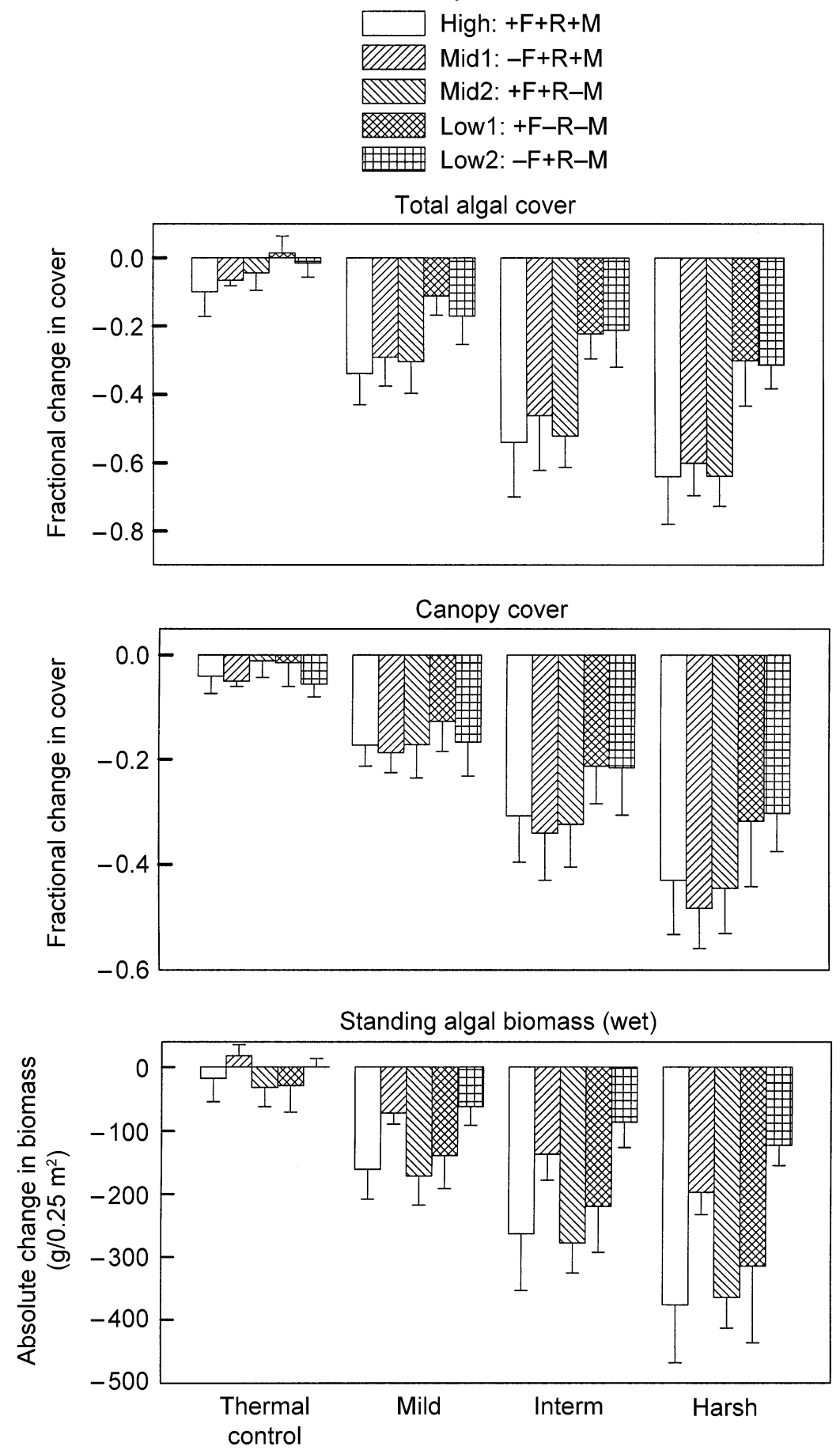

Heat level

FIG. 2. Resistance: change in community variables measured by fraction of original cover or total biomass lost due to thermal stress. Error bars represent $1 \mathrm{SE}(n=5)$. 


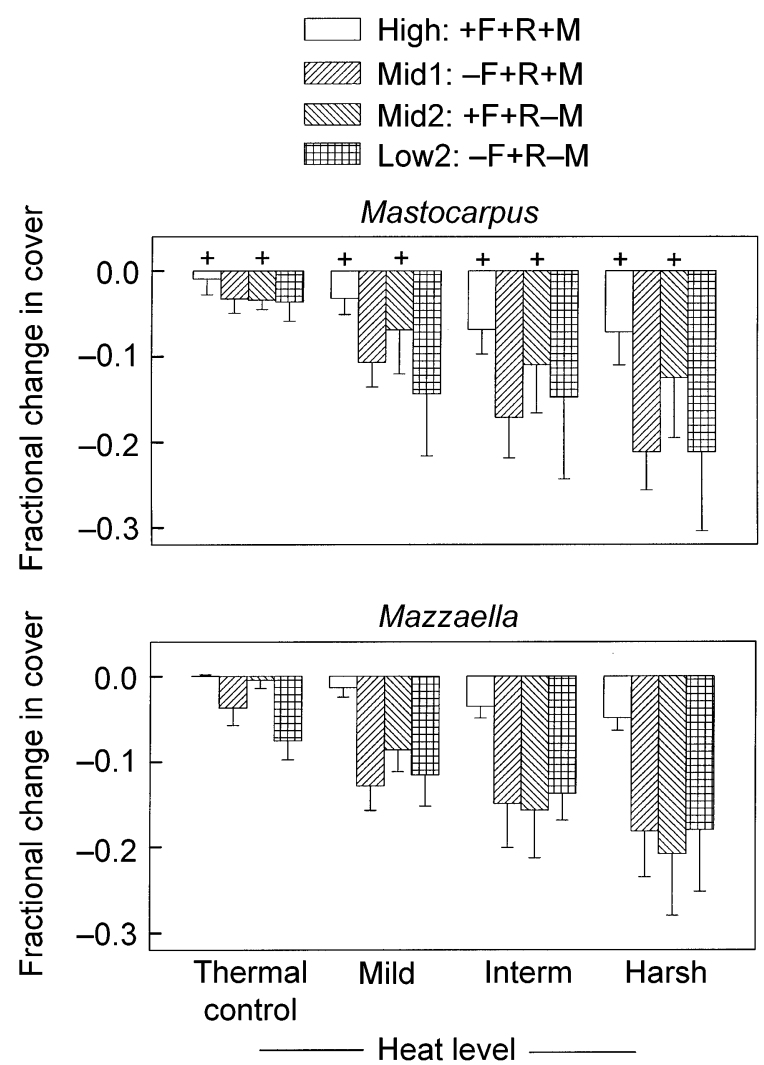

FIG. 3. Resistance: change in cover of foliose red species measured by fraction of original cover lost due to thermal stress. Only diversity treatments that did not exclude foliose red species are shown. Treatments in which fucoids were included are indicated by "+." Error bars represent 1 SE ( $n$ $=5)$.

no one species was strongly affected whereas another species was only weakly affected.

\section{Resilience}

The extensive community effects of the heat treatment were evident in the severe areas (compare Fig. $6 \mathrm{~A}$ and $\mathrm{B}$ to Fig. 6C). The differences among treatments, obvious just one month before (Fig. 1B) were removed by the perturbation. None of the severe areas

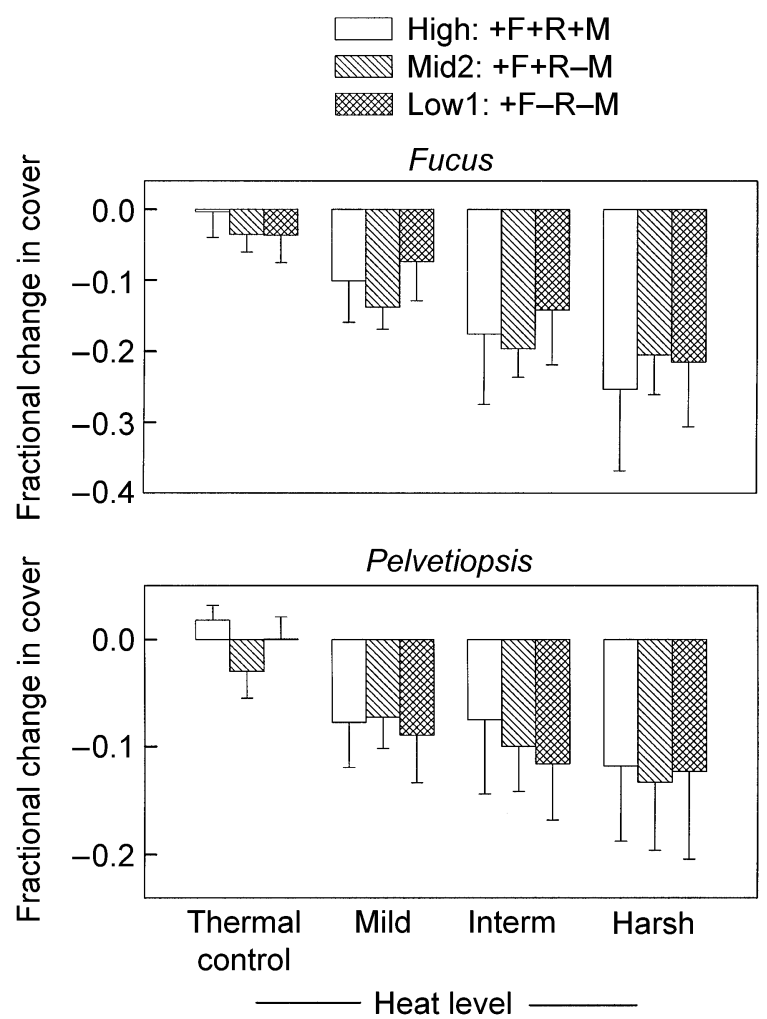

FIG. 4. Resistance: change in cover of fucoids measured by fraction of original cover lost due to thermal stress. Only diversity treatments that did not exclude fucoids are shown. Error bars represent 1 SE $(n=5)$.

were similar to reference plots and there was more variation among the reference plots than among all disturbed plots (Fig. 6C). Over the next $21 \mathrm{mo}$, these disturbed areas gradually diverged (Fig. 6C, F, I). Yet, by the end of that period only a few areas were similar to the reference plots (Fig. 6I).

The moderate areas showed lesser effects, but differences from thermal control treatments were still apparent. Immediately after the stress, few of the stressed treatments clustered with the reference plots (Fig. 6B), unlike thermal control plots (Fig. 6A). After 21 mo,

TABLE 5. ANOVA results for proportional change in response to thermal stress among major species: Fucus, Pelvetiopsis, Mazzaella, and Mastocarpus.

\begin{tabular}{|c|c|c|c|c|c|c|c|c|c|c|}
\hline \multirow[b]{3}{*}{ Source } & \multirow[b]{3}{*}{ df } & \multicolumn{9}{|c|}{ Heat-intensity level } \\
\hline & & \multicolumn{3}{|c|}{ Mild } & \multicolumn{3}{|c|}{ Intermediate } & \multicolumn{3}{|c|}{ Harsh } \\
\hline & & MS & $F$ & $P$ & MS & $F$ & $P$ & MS & $F$ & $P$ \\
\hline Stress & 1 & 2.07 & 22.35 & 0.0001 & 5.743 & 72.9 & 0.0001 & 7.75 & 68.6 & 0.0001 \\
\hline Species & 3 & 0.266 & 2.87 & 0.0379 & 0.159 & 2.02 & 0.1130 & 0.154 & 1.36 & 0.2550 \\
\hline Species $\times$ stress & 3 & 0.239 & 2.57 & 0.0559 & 0.158 & 2.00 & 0.1150 & 0.276 & 2.44 & 0.0656 \\
\hline Block & 4 & 0.278 & 2.99 & 0.0201 & 0.350 & 4.44 & 0.0019 & 0.214 & 1.90 & 0.1125 \\
\hline Error & 184 & 0.0929 & & & 0.0787 & & & 0.113 & & \\
\hline
\end{tabular}

Notes: Each test (Mild, Intermediate, and Harsh) is a comparison of the stressed areas to the control areas with the four species as a class effect. Because of the multiple comparisons to the control plots, criteria for significance is by Dunn-Sidák criteria $(\alpha=0.05$ at $P<0.0169)$. Boldface type indicates a significant effect. 


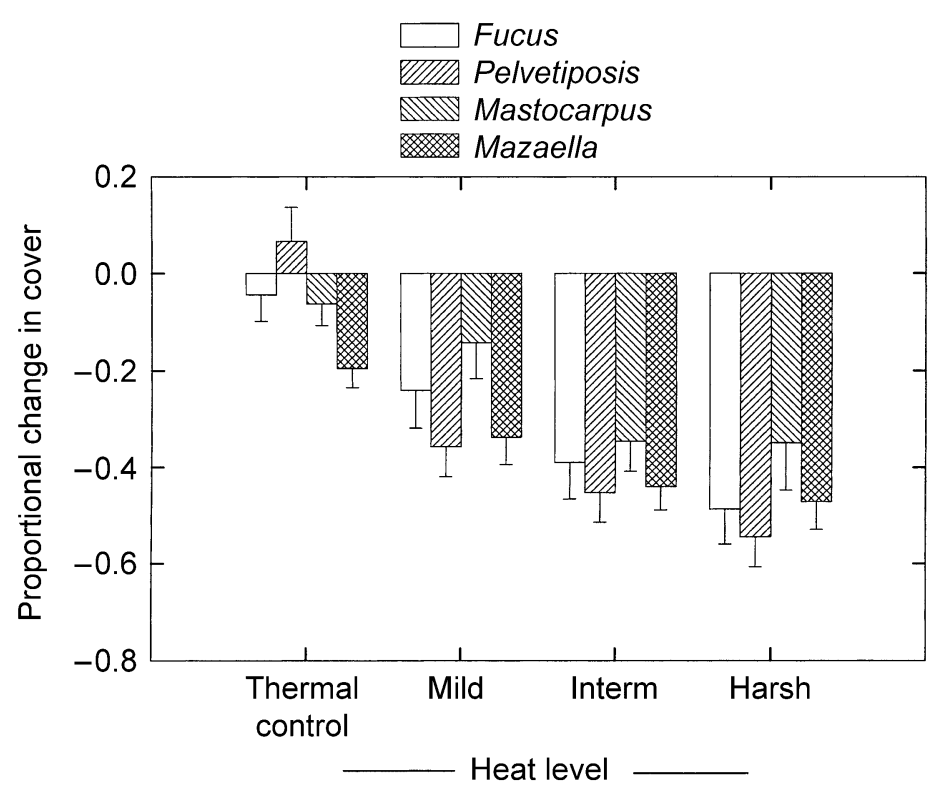

FIG. 5. Relative sensitivity to thermal stress for major algal species. The histogram bars indicate proportional change in cover, using all treatments in which the species was not excluded.

many thermal control plots had become similar to the reference plots although several of low1, mid1, and low2 plots were still outside of the reference cluster (Fig. 6G). But for the moderate treatment, many more plots were outside of the reference cluster and the total variation across all plots was still much greater than among the reference plots (Fig. 6B, E, H).

\section{Community states}

Reference plots.-The predominant state within the reference plots throughout the experiment was fucoid dominated (Fig. 7). More than $75 \%$ of these subplots remained in the fucoid state. Areas dominated by foliose red species also persisted but were less abundant in overall area. Other states that occurred were transient: Cladophora-dominated, Balanus/Endocladiadominated, and barnacle-dominated states might persist for up to a year but would then change to other states, often to the fucoid-dominated state. Although bare rock occurred and was created in these plots, it was not spatially extensive enough in any reference subplot to force that sample unit to the bare rock-dominated state.

Recovery in thermal-control plots.-The resilience to a species deletion perturbation (sensu Pimm 1980), demonstrated in the thermal control treatments, was predominantly determined by the initial deviation away from the reference condition. Two higher diversity treatments (Fig. 8; high, mid2) were closest to the reference plots at the start of the resilience period (Fig. 1B). For these treatments, the primary state throughout the resilience period was fucoid-dominated, though other states were present but not persistent. Unlike the reference plots, the foliose-red-dominated state was not persistent throughout this period in these two treatments. In the low-diversity fucoid treatment (low1:
+F-R-M), at the start of the resilience period, the barnacle-dominated state occupied as many subplots as the fucoid state (Fig. 8). The release of the diversity press in these plots led to a slow progression to states similar to the reference condition.

In addition, the absence of fucoids in thermal control treatments (Fig. 8; mid1, low2) showed slow recovery to the reference condition especially in the lowest diversity treatment. At the start of the resilience period, the mid1 diversity treatment was primarily in the foliose-red-dominated state. Within 8 mo, a majority of subplots had made the transition to the fucoid-dominated state and all of the subplots previously dominated by Balanus/Endocladia made the transition to the fucoid state by 14 mo. Further, by the end of the monitored resilience period, the proportion of states in this treatment was roughly equivalent to the reference plots. However, the low2 diversity treatment (Fig. 8) showed little recovery to a primarily fucoid-dominated community. Although the states of low 2 were similar to mid1 at the start of the resilience period, the foliosered-dominated state persisted throughout that period in the low-diversity treatment. Thus, the persistence of stages that were typically not dominant in the reference plots slowed the resilience of this low-diversity treatment to reference-like composition.

Recovery in disturbed plots.-Within severe areas, although similar in the early phases, plots diverged by the end of the monitored period such that treatments that began most similar to the reference (high, mid2) returned to reference-like states whereas those that began less similar remained quite unlike the references (Fig. 9). Initially, the thermal stress reset all states to bare rock dominated. The primary community trajectory for all treatments in these strongly affected areas was a progression from bare rock through barnacle 
Diversity treatments

O High: $+\mathrm{F}+\mathrm{R}+\mathrm{M}$

$\nabla$ Mid1: $-\mathrm{F}+\mathrm{R}+\mathrm{M}$

a Mid2: $+\mathrm{F}+\mathrm{R}+\mathrm{M}$

$\triangle$ Low1: +F-R-M

$\diamond$ Low2: $-\mathrm{F}+\mathrm{R}-\mathrm{M}$

- Reference plots

Perturbation level

Thermal

control
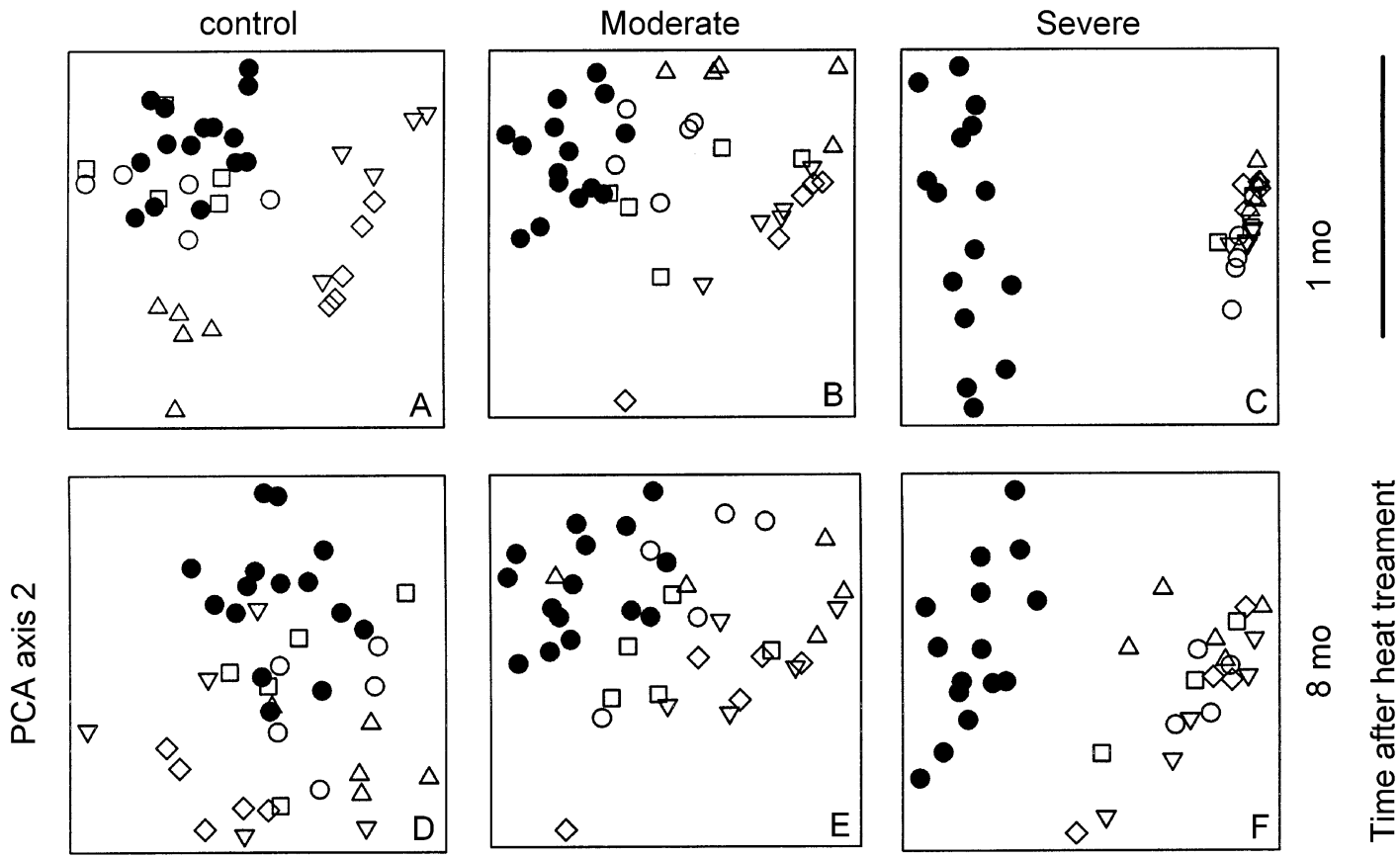

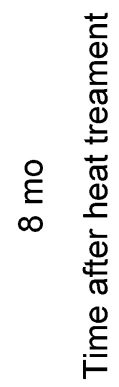
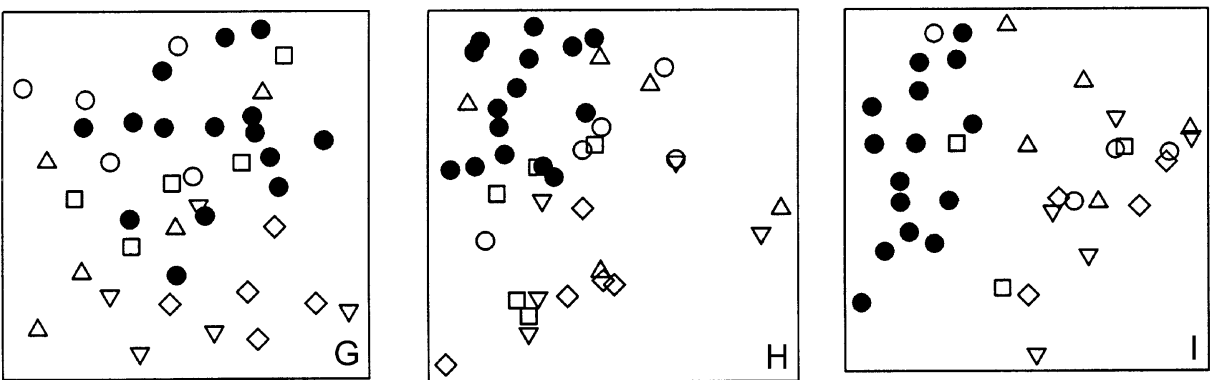

$\stackrel{\circ}{\check{\Sigma}}$

PCA axis 1

FIG. 6. Principal components analysis of the community trajectory for three stress levels: thermal control, moderate, and severe. See Fig. 1 for more details. Loadings (percent variance) for axis 1, loadings for axis 2, and the number of significant axes, respectively, are: (A) 45.9, 33.6, 2; (B) 54.5, 24.7, 2; (C) 84.6, 6.1, 1; (D) 46.9, 30.0, 2; (E) 52.1, 24.9, 2; (F) 73.1, $10.0,1 ;(\mathrm{G}) 44.9,28.3,2 ;(\mathrm{H}) 47.0,31.1,2$; and (I) 72.8, 12.9, 1.

stages and eventually to algal-dominated states. By the end of the monitored resilience period, the treatments originally most similar to the reference plots (Fig. 9; high, mid2) were again composed of reference-like states, though the abundance of the fucoid state was not dominant. The low-diversity, fucoid-only treatment (low1, Fig. 9), was similar although no foliose-reddominated states appeared. The two treatments from which fucoids had been excluded during the diversity press (mid1, low2) showed early recovery patterns similar to the +fucoid treatments but the fucoid state never appeared during the monitored resilience period (Fig. 


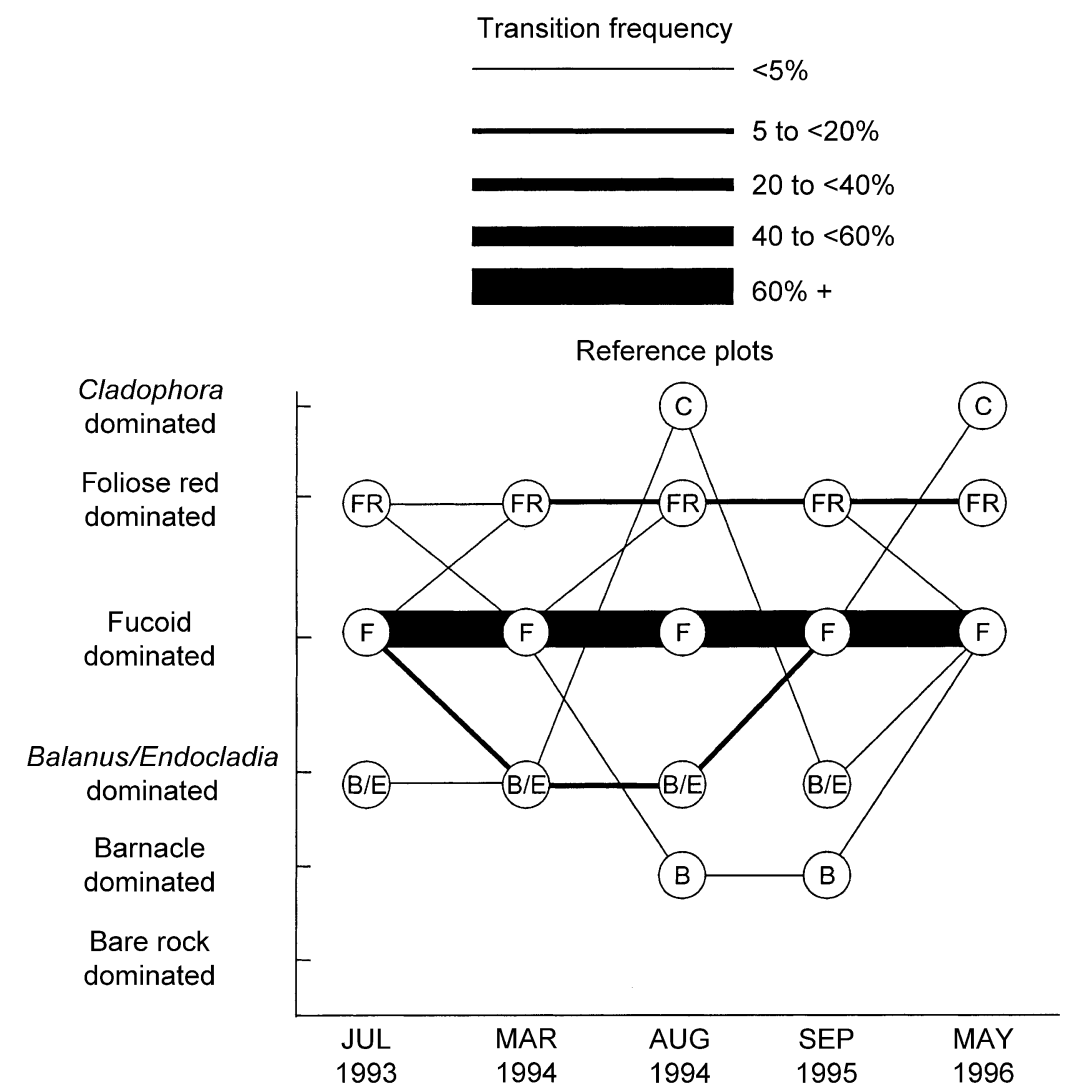

FIG. 7. State diagram for the reference plots. The figure illustrates a sample of five survey periods during the experiment to demonstrate typical variation of nonmanipulated plots. Circles represent one of the six community states described in the Methods section. The key indicates how line thickness denotes the percentage of experimental areas making the transition between states across time. Thick lines indicate the dominant transitions and states. States that do not occur during a survey are not shown.

9). Further, there is a clear effect of local recruitment into the severe areas. Return of species already present in the moderate area of a plot was much quicker than the return of previously excluded species. Within moderate areas (Fig. 10), recovery was quite variable among compositional treatments.

Thus, the level of stress and composition interacted to produce different recovery patterns. The transition to reference-like states in the low-diversity treatments were clearly longer than in the higher diversity treatments either because of the persistence of nonprevalent states (low2; FR dominated) or the lack of return of some common states (low1; FR absent) and this occurred at all perturbation levels. The higher diversity treatments with fucoids (high, mid2) began the resilience period initially similar to the reference set (thermal control), recovered to such states quickly (moderate) or only slowly returned to such states (severe). The mid-diversity, fucoid-exclusion treatment (mid1) was initially very different from the reference plots but with no stress, returned fairly quickly to the reference condition (Fig. 8). Moderate perturbation slowed that recovery to fucoid states and the severe perturbation prevented their return altogether within the monitored period.

\section{DISCUSSION}

Among the numerous factors that have been proposed to influence community stability such as productivity (Stone et al. 1996), disturbance regime (Guichard et al. 2003), and scale effects (Steele 1985, Rahel 1990), the role of diversity has been the most contentious. My experiment demonstrates that the influence of diversity on community dynamics is not simple and will depend on the characteristics of the stress as well as the characteristics of the species present in the community. Furthermore, factors such as the local regeneration pool, the life history characteristics of dominant species, and the persistence of nonprevalent states can modify the manifestation of a diversity effect.

\section{Resistance}

This experiment illustrated several ways in which differences in composition can modify the proximate effect of a strong perturbation. Because there were initial differences among diversity treatments in abun- 


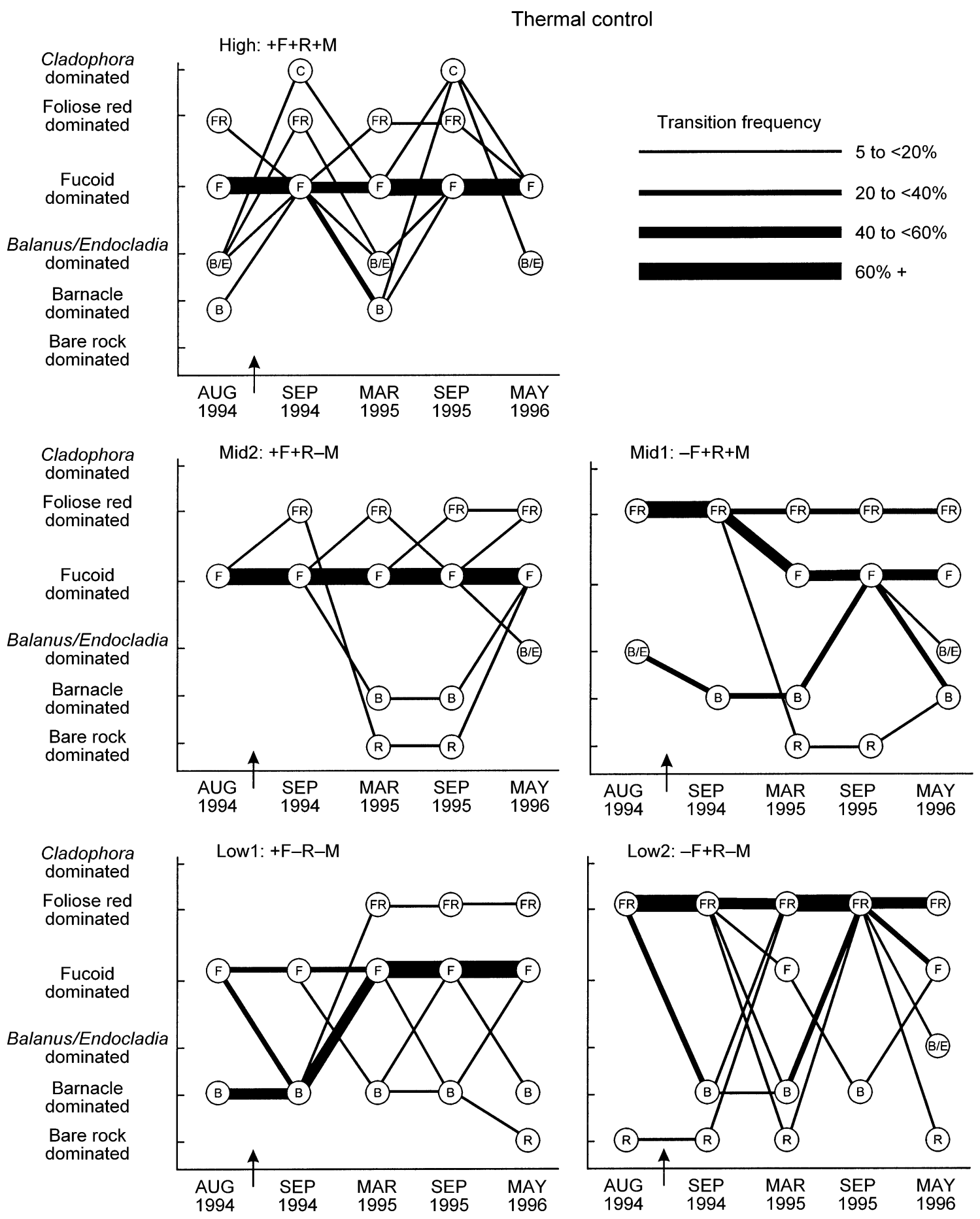

FIG. 8. State diagram for thermal control subplots, all diversity treatments. Arrows indicate the point in time that the diversity press was released. See Fig. 7 for more details.

dance, biomass, and cover, and the perturbation directly affected those measures, the higher diversity treatments, especially those with fucoids, lost more from the thermal stress. Thus, in cases where higher diversity areas are more productive (Naeem et al. 1994, Tilman et al. 1996, Hector et al. 1999), they will have more to lose from a given stress. These results are similar to grassland experiments (Tilman and Downing 1994, Pfisterer and Schmid 2002) where plots with the highest biomass lost the most during a extensive drought. However, in the Tilman and Downing study, high biomass treatments were the low-diversity treatments and thus 


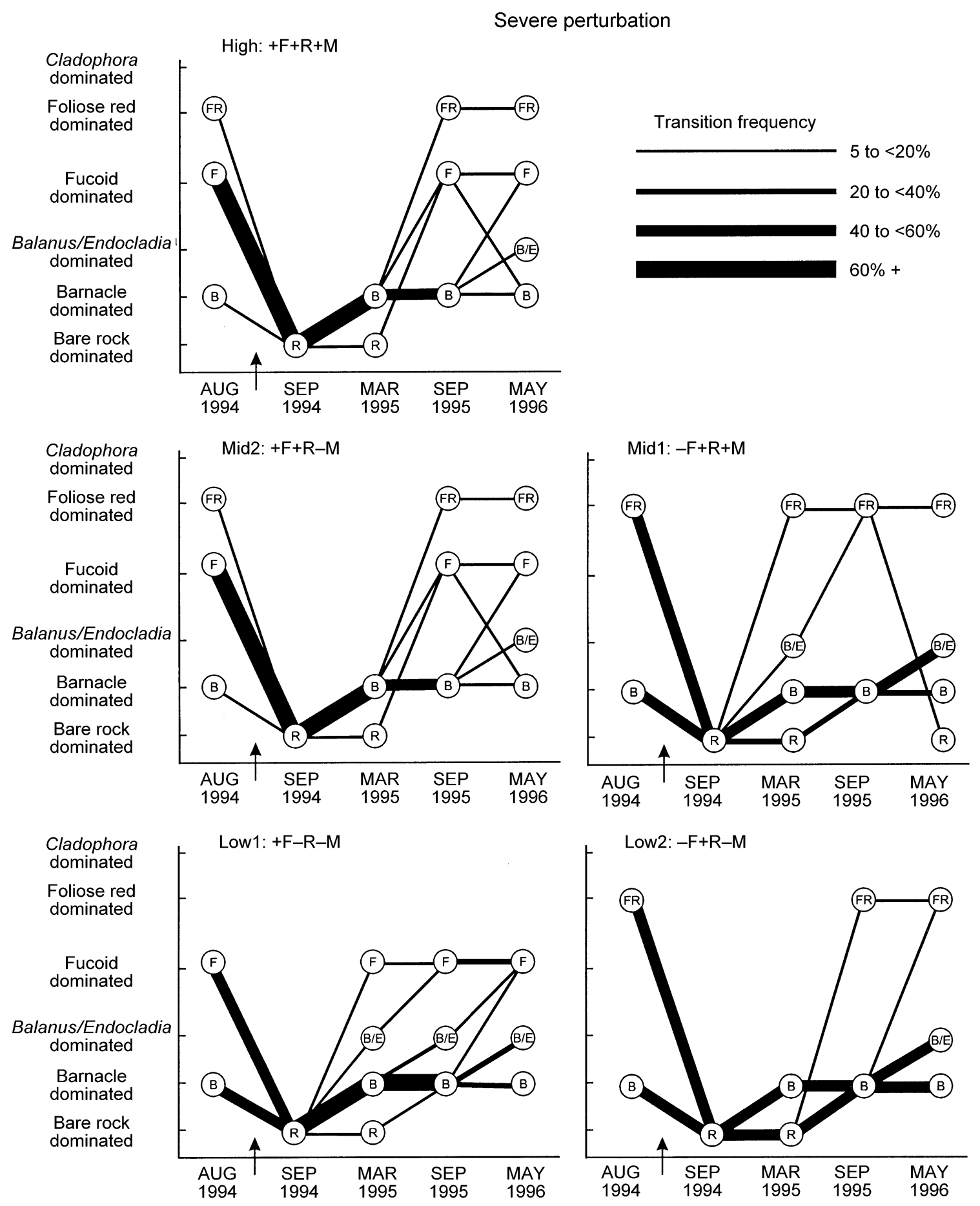

FIG. 9. State diagram for severe perturbation subplots, all diversity treatments. Arrows indicate the point in time that the diversity press was released and the thermal stress was applied. See Fig. 7 for more details.

low-diversity treatments were the most severely affected. These results are consistent with an alternative argument (Pfisterer and Schmid 2002) to the insurance hypothesis: more speciose systems are likely to include more sensitive species and unless compensation is rap- id and complete, more diverse systems will be more affected, not less.

However, the heat stress was largely nonselective. Effects attributable to diversity will be caused by some variation among species such as how strongly the spe- 


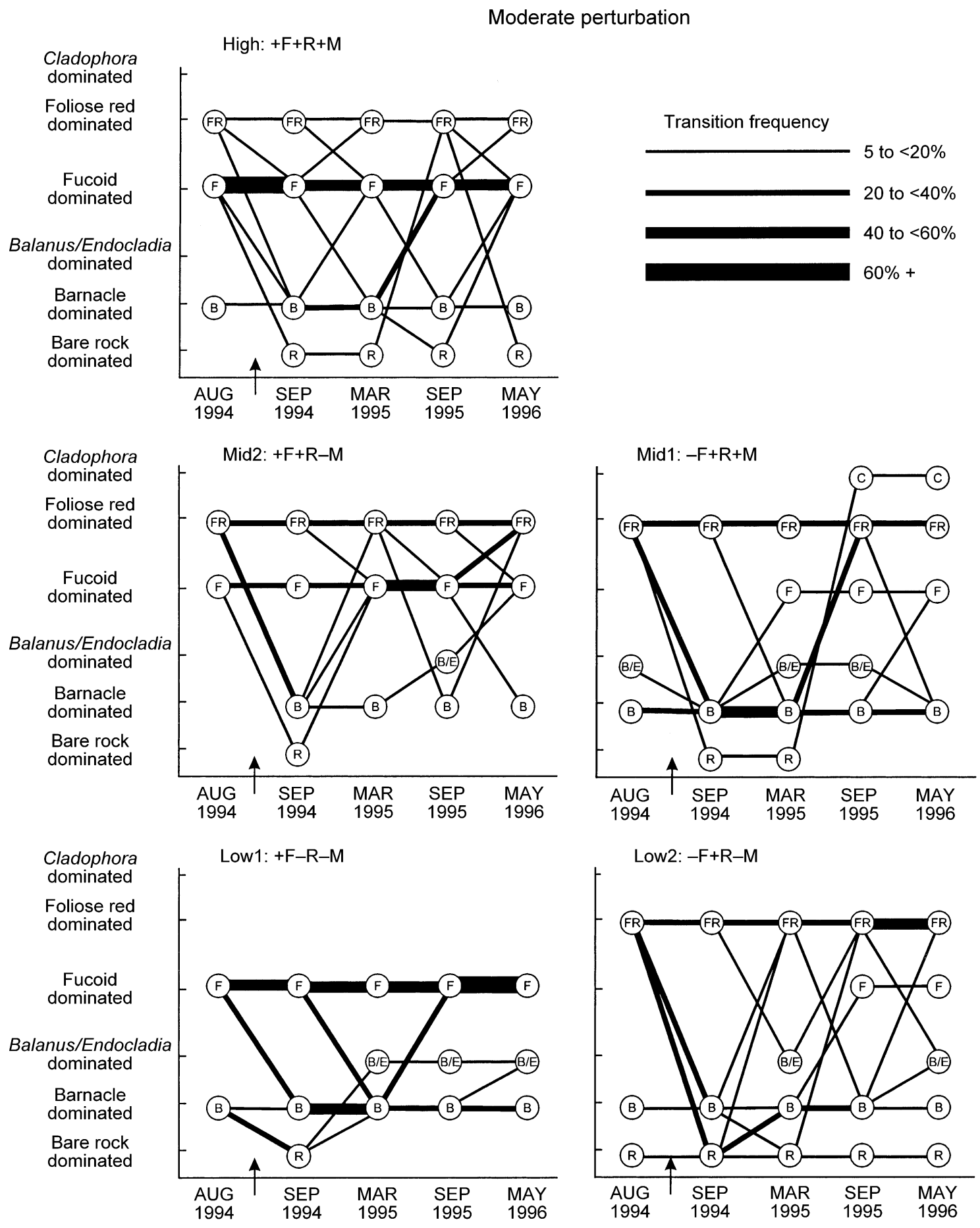

FIG. 10. State diagram for moderate perturbation subplots, all diversity treatments. Arrows indicate the point in time that the diversity press was released and the thermal stress was applied. See Fig. 7 for more details.

cies are affected by the stress, how species protect themselves from a stress, or even how the species change the disturbance regime (Denslow 1996). However, if a stress affects all species in similar ways, we should expect diversity to have little influence. Although the morphology of the manipulated species in this community varied widely, the intensity of this thermal stress overwhelmed these differences such that no species was proportionately less affected. The selectivity of a stress will depend at least on the magnitude and type of disturbing force and the characteristics of the species affected (Sousa 1985), with greater forces 
more likely to overwhelm species characteristics. Thus, one class of stresses that are likely to be nonselective is catastrophic perturbations and diversity will have little influence in such disturbances.

\section{Resilience}

Recovery from large deviations caused by the species perturbations (Fig. 8; low1, low2) was clearly dependent on which species were present. When only the fucoids were present at the start of recovery (low1), the collection of plots returned to states similar to the reference in less than a year. However, when Mastocarpus and Mazzaella were the only starting species (low2), fucoid dominance did not return throughout the resilience period. In contrast, recovery from large deviations caused by the thermal stress (Fig. 9) produced similar recovery pathways among diversity treatments: rock dominated, followed by barnacle dominated, followed by some algal dominance. These severe treatments later diverged in that the fucoid-excluded treatments did not develop any fucoid states in the 21-mo resilience period.

Two patterns related to the slow recovery in the two low-diversity treatments suggest mechanisms for the differences: persistence of a nonreference condition and lack of a dominant group. In the low-diversity treatment low1, the initial absence of the species that made up that persistent state (foliose reds) made full recovery to the reference condition slower. Throughout the monitored period (almost two years), the foliose-red state never appeared in these stressed plots. The two species that are the main components of this state, Mastocarpus and Mazzaella, have life history characteristics that do not facilitate rapid colonization. Mazzaella propagates primarily through vegetative growth. Although Mazzaella is resilient to damage to blades, removal of or damage to the crust severely retards its ability to recover (Olson 1985). Similarly Mastocarpus has a thick crust stage that is remarkably resilient to many stresses (Dethier 1987), although the blades are less so. Apparently the persistent removal of recruits from treatment low 1 during the diversity press combined with the thermal stress which may have damaged any residual crusts, removed even the most resistant stages of the species. In the treatments in which fucoids had been excluded (mid1 and low2), the foliose-red (FR) state was quite persistent as the dominant state. This was particularly true for the lower diversity treatment. This persistence in the low-diversity treatment (low2 compared to mid1), may be attributable to the facilitation of fucoid recruitment by minor species (Allison 1997).

There was also a clear effect of the local "regeneration pool" (sensu Denslow 1996) on resilience and recolonization of algal species into these plots. If a species had been excluded from a plot during the diversity press, it returned much more slowly to even the severely perturbed areas than to plots in which a species had not been excluded (note the absence of fucoid states in mid 1 and low 2 and the absence of the foliosered state in low1, Figs. 9 and 10). These experimental plots were slightly larger than $1 \mathrm{~m}$ on a side and, for most species, propagule sources were within a few meters. However, the dependence of recovery on the presence of the species within the experimental plot suggests either a dependence on very close propagule sources or some facilitation of recruitment (e.g., Type I, Sousa 1985). Sousa (1984) found similar dynamics for algal succession in patches made in mussel beds and research in communities similar to this experiment (Farrell 1989, Kim and DeWreede 1996) have suggested similar, highly local recruitment dynamics (but see Menge et al. 1993 for low zone dynamics). These results imply that even local species reductions may lead to dynamics dependent on which species remain.

In the insurance hypothesis, Yachi and Loreau (1999) posit that higher diversity will both buffer temporal variance and increase the temporal mean of system productivity. While the resilience results of this experiment are consistent with the insurance hypothesis, the resistance results do not support this hypothesis in that at least some of the higher diversity treatments lost more to the stress. This apparent tradeoff between poorer resistance but better resilience of some treatments indicates that diversity's influence on the overall temporal mean of productivity in this system will depend on the characteristics of the disturbance regime, in particular, the frequency and intensity of events. More generally, the influence of diversity on the overall dynamics of a system is likely to be strongly contingent on the characteristics of the stress and the characteristics of the removed species.

\section{ACKNOWLEDGMENTS}

M. Hixon, J. Lubchenco, B. Mansfield, B. McCune, and especially B. Menge made important contributions on early manuscripts. P. Morin, R. Etter, and an anonymous reviewer made excellent suggestions to a pair of later manuscripts. B. Mansfield and J. Mohler assisted with fieldwork. Work on this project was supported by a National Science Foundation predoctoral fellowship to G. Allison and an Andrew W. Mellon Foundation grant to J. Lubchenco and B. Menge. This is contribution number 116 of the Partnership for Interdisciplinary Studies of Coastal Oceans (PISCO): A Long-Term Ecological Consortium funded by the David and Lucile Packard Foundation. This work formed part of the dissertation requirement for the Ph.D. in the Department of Zoology, Oregon State University.

\section{Literature Cited}

Allison, G. W. 1997. Ecological consequences of the reduction of species diversity: experimental approaches. Dissertation. Oregon State University, Corvallis, Oregon, USA.

Allison, G. W. 1999. The implications of experimental design for biodiversity manipulations. American Naturalist 153: 26-45.

Chapman, A. R. O. 1995. Functional ecology of fucoid algae: twenty-three years of progress. Phycologia 34:1-32.

Connell, J. H. 1974. Ecology: field experiments in marine ecology. Pages 21-54 in R. N. Mariscal, editor. Experi- 
mental marine biology. Academic Press, New York, New York, USA.

Connell, J. H., and W. P. Sousa. 1983. On the evidence needed to judge ecological stability or persistence. American Naturalist 121:789-824.

Davison, I. R., and G. A. Pearson. 1996. Stress tolerance in intertidal seaweeds. Journal of Phycology 32:197-211.

Dayton, P. K. 1971. Competition, disturbance, and community organization: the provision and subsequent utilization of space in a rocky intertidal community. Ecological Monographs 41:351-389.

Denslow, J. S. 1996. Functional group diversity and responses to disturbance. Pages 127-151 in G. H. Orians, R. Dirzo, and J. H. Cushman, editors. Biodiversity and ecosystem processes in tropical forests. Springer-Verlag, Berlin, Germany.

Dethier, M. N. 1987. The distribution and reproductive phenology of intertidal fleshy crustose algae in Washington. Canadian Journal of Botany 65:1838-1850.

Doak, D. F., D. Bigger, E. K. Harding, M. A. Marvier, R. E. O'Malley, and D. Thomson. 1998. The statistical inevitability of stability-diversity relationships in community ecology. American Naturalist 151:264-276.

Elton, C. S. 1958. The ecology of invasions by animals and plants. Wiley, London, UK.

Farrell, T. M. 1988. Community stability: effects of limpet removal and reintroduction in a rocky intertidal community. Oecologia 75:190-197.

Farrell, T. M. 1989. Succession in a rocky intertidal community: the importance of disturbance size and position within a disturbed patch. Journal of Experimental Marine Biology and Ecology 128:57-73.

Farrell, T. M. 1991. Models and mechanisms of succession: an example from a rocky intertidal community. Ecological Monographs 61:95-113.

Frank, D. A., and S. J. McNaughton. 1991. Stability increases with diversity in plant communities: empirical evidence from the 1988 Yellowstone drought. Oikos 62:360-362.

Glynn, P. W. 1965. Community composition, structure, and interrelationships in the marine intertidal Endocladia muricata-Balanus glandula association in Monterey Bay, California. Beaufortia 12:1-198.

Griffiths, B. S., K. Ritz, R. D. Bardgett, R. Cook, S. Christensen, F. Ekelund, S. J. Sorensen, E. Baath, J. Bloem, P. C. de Ruiter, J. Dolfing, and B. Nicolardot. 2000. Ecosystem response of pasture soil communities to fumigationinduced microbial diversity reductions: an examination of the biodiversity-ecosystem function relationship. Oikos 90:279-294.

Guichard, F., P. M. Halpin, G. W. Allison, J. Lubchenco, and B. A. Menge. 2003. Mussel disturbance dynamics: sig natures of oceanographic forcing from local interactions. American Naturalist 161:889-904.

Hay, M. E. 1981. The functional morphology of turf-forming seaweeds: persistence in stressful marine habitats. Ecology 62:739-750.

Hector, A., et al. 1999. Plant diversity and productivity experiments in European grasslands. Science 286:1123-1127.

Holling, C. S. 1973. Resilience and stability of ecological systems. Annual Review of Ecology and Systematics 4:123.

Kim, J. H., and R. E. DeWreede. 1996. Effects of size and season of disturbance on algal patch recovery in a rocky intertidal community. Marine Ecology Progress Series 133: $217-228$

Knops, J., D. Tilman, N. M. Haddad, S. Naeem, C. E. Mitchell, J. Haarstad, M. E. Ritchie, K. M. Howe, P. B. Reich, E. Siemann, and J. Groth. 1999. Effects of plant species richness on invasion dynamics, disease outbreaks, insect abundances, and diversity. Ecology Letters 2:286-293.
Levin, S. A., and R. T. Paine. 1974. Disturbance, patch formation and community structure. Proceedings of the National Academy of Science (USA) 71:2744-2747.

Levine, J. M. 2000. Species diversity and biological invasions: relating local process to community pattern. Science 288:852-854.

Loreau, M., and N. Behera. 1999. Phenotypic diversity and stability of ecosystem process. Theoretical Population Biology 56:29-47.

Loreau, M., A. Downing, M. Emmerson, A. Gonzalez, J. Hughes, P. Inchausti, J. Joshi, J. Norberg, and O. Sala. 2002. A new look at the relationship between diversity and stability. Pages 79-91 in M. Loreau, S. Naeem, and P. Inchausti, editors. Biodiversity and ecosystem functioning: synthesis and perspectives. Oxford Press, Oxford, UK.

Loreau, M., S. Naeem, P. Inchausti, J. Bengtsson, J. P. Grime, A. Hector, D. U. Hooper, M. A. Huston, D. Raffaelli, B. Schmid, D. Tilman, and D. A. Wardle. 2001. Biodiversity and ecosystem functioning: current knowledge and future challenges. Science 294:804-808.

Lubchenco, J., and J. Cubit. 1980. Heteromorphic life histories of certain marine algae as adaptations to variations in herbivory. Ecology 61:676-687.

May, R. M. 1973. Stability and complexity in model ecosystems. Princeton University Press, Princeton, New Jersey, USA.

McGrady-Steed, J., P. M. Harris, and P. J. Morin. 1997. Biodiversity regulates ecosystem predictability. Nature 390: 162-165.

McNaughton, S. J. 1993. Biodiversity and function of grazing ecosystems. Pages 361-383 in E.-D. Schulze and H. A. Mooney, editors. Biodiversity and ecosystem function. Springer-Verlag, Berlin, Germany.

Menge, B. A., T. M. Farrell, A. M. Olson, P. van Tamelen, and T. Turner. 1993. Algal recruitment and the maintenance of a plant mosaic in the low intertidal region on the Oregon coast. Journal of Experimental Marine Biology and Ecology 170:91-116.

Menge, B. A., A. M. Olson, and E. Dahlhoff. 2002. Environmental stress, bottom-up effects, and community dynamics: integrating molecular-physiological with ecological approaches. Integrative and Comparative Biology 42: 892-908.

Menge, B. A., and J. P. Sutherland. 1987. Community regulation: variation in disturbance, competition, and predation in relation to environmental stress and recruitment. American Naturalist 130:730-757.

Mulder, C. P. H. 2001. Physical stress and diversity-productivity relationships: the role of positive interactions. Proceedings of the National Academy of Science (USA) 98: 6704-6708.

Naeem, S., and S. B. Li. 1997. Biodiversity enhances ecosystem reliability. Nature 390:507-509.

Naeem, S., L. J. Thompson, S. P. Lawler, J. H. Lawton, and R. M. Woodfin. 1994. Declining biodiversity can alter the performance of ecosystems. Nature 368:734-737.

Olson, A. M. 1985. Early succession in bed of the red alga, Iridaea cornucopiae Post. and Rupr. (Gigartinaceae): alternate pathways. Thesis. Oregon State University, Corvallis, Oregon, USA.

Orians, G. H. 1975. Diversity, stability and maturity in natural ecosystems. Pages 139-150 in W. H. van Dobben and R. H. Lowe-McConnell, editors. Unifying concepts in ecology. Dr. W. Junk B. V. Publishers, The Hague, The Netherlands.

Paine, R. T., and S. A. Levin. 1981. Intertidal landscapes: disturbance and the dynamics of pattern. Ecological Monographs 51:145-178.

Petchey, O. L., P. T. McPhearson, T. M. Casey, and P. J. Morin. 1999. Environmental warming alters food-web structure and ecosystem function. Nature 204:69-72. 
Pfisterer, A. B., and B. Schmid. 2002. Diversity-dependent production can decrease the stability of ecosystem functioning. Nature 416:84-86.

Pimm, S. L. 1980. Food web design and the effect of species deletion. Oikos 35:139-149.

Pimm, S. L. 1984. The complexity and stability of ecosystems. Nature 307:321-326.

Pimm, S. L. 1991. The balance of nature? University of Chicago Press, Chicago, Illinois, USA.

Rahel, F. J. 1990. The hierarchical nature of community persistence: a problem of scale. American Naturalist 136:328344.

Sokal, R. R., and F. J. Rohlf. 1981. Biometry: the principles and practice of statistics in biological research. Second edition. W. H. Freeman, New York, New York, USA.

Sousa, W. P. 1979. Disturbance in marine intertidal boulder fields: the nonequilibrium maintenance of species diversity. Ecology 60:1225-1239.

Sousa, W. P. 1984. Intertidal mosaics: patch size, propagule availability, and spatially variable patterns of succession. Ecology 65:1918-1935.

Sousa, W. P. 1985. Disturbance and patch dynamics on rocky intertidal shores. Pages 101-124 in S. T. A. Pickett and P. S. White, editors. The ecology of natural disturbance and patch dynamics. Academic Press, San Diego, California, USA.

Sousa, W. P. 2001. Natural disturbance and the dynamics of marine benthic communities. Pages 85-130 in M. D. Bertness, S. D. Gaines, and M. E. Hay, editors. Marine com- munity ecology. Sinauer Associates, Sunderland, Massachusetts, USA.

Stachowicz, J. J., R. B. Whitlatch, and R. W. Osman. 1999. Species diversity and invasion resistance in a marine ecosystem. Science 286: $1577-1579$.

Steele, J. H. 1985. A comparison of terrestrial and marine ecological systems. Nature 313:355-358.

Stone, L., A. Gabric, and T. Berman. 1996. Ecosystem resilience, stability, and productivity: seeking a relationship. American Naturalist 148:892-903.

Tilman, D., and J. A. Downing. 1994. Biodiversity and stability in grasslands. Nature 367:363-365.

Tilman, D., J. Knops, D. Wedin, and P. Reich. 2001. Experimental and observational studies of diversity, productivity, and stability. Pages $42-70$ in A. P. Kinzig, S. Pacala, and D. Tilman, editors. The functional consequences of biodiversity: empirical progress and theoretical extensions. Princeton University Press, Princeton, New Jersey, USA.

Tilman, D., C. L. Lehman, and K. T. Thomson. 1997. Plant diversity and ecosystem productivity: theoretical considerations. Proceedings of the National Academy of Science (USA) 94:1857-1861.

Tilman, D., D. Wedin, and J. Knops. 1996. Productivity and sustainability influenced by biodiversity in grassland ecosystems. Nature 379:718-720.

Yachi, S., and M. Loreau. 1999. Biodiversity and ecosystem productivity in a fluctuating environment: the insurance hypothesis. Proceedings of the National Academy of Sciences (USA) 96:1463. 